\title{
EN EL PRINCIPIO... FUE EL DESEO. LA CONSTITUCIÓN DEL YO EN METAFÍSICA DE LOS TUBOS: UNA LECTURA DESDE LA TEORÍA PSICOANALÍTICA
}

\author{
Rosa Durá Celma \\ Universitat de València
}

A Teresa Fernández, maestra en escuchar

\begin{abstract}
RESUMEN: Este artículo hace una propuesta de lectura de la novela de Amélie Nothomb Metafísica de los tubos (Métaphysique des tubes) desde una perspectiva literaria que tiene como modelo teórico el psicoanálisis lacaniano. En esta línea, analizaremos cómo esta autoficción formaliza algunas de las fases que intervienen en la constitución subjetiva -prestando especial atención a la noción de deseo-, y a cómo estas se concretan, formal y temáticamente, en la estrategia de escritura que adopta la autora. Asimismo, se estudiará el impacto que el orden simbólico tiene en la construcción del personaje-sujeto y el juego con la focalización que plantea la novela.
\end{abstract}

PALABRAS CLAVE: Autoficción, constitución subjetiva, deseo, focalización, psicoanálisis, resortes de escritura.

\section{AT THE BEGINNING... THERE WAS THE DESIRE. THE CONSTITUTION OF THE SELF IN THE CHARACTER OF RAIN: AN INTERPRETATION FROM A PSYCHOANALYTIC POINT OF VIEW}

\footnotetext{
ABSTRACT: This paper proposes an interpretation of Amélie Nothomb's novel The Character of Rain (Métaphysique des tubes) from a literary perspective and adopts the theoretical model put forward in the lacanian psychoanalysis. From this point of view we discuss how this autofiction formalizes some of the steps involved in the subjective constitution paying special attention to the notion of desire, and how these are specified, formally and thematically, in the writing strategy the author
} 
adopts. We will examine also the impact which the symbolic order has on the building of the subject-and the way the novel plays with the focus point of view.

KEYWORDS: Autofiction, subjective constitution, desire, focus, psychoanalysis, writing strategy.

Nosotros consideramos, entonces, el conjunto de un texto como los alrededores de una falta, principio de la acción de la estructura, que lleva, por lo tanto, las marcas de la acción que la realiza: la sutura.

-Jacques-Alain Miller-

\section{Introducción}

La original novela de Amélie Nothomb, Metafísica de los tubos, se publicó en España en el 2001. La escritura de esta autora se caracteriza, entre otras muchas cosas, por su habilidad para manipular novelísticamente su propia biografía. Dentro de ese itinerario vital, la infancia ocupa un lugar preeminente y se convierte en uno de los temas más recurrentes de su narrativa, sobre todo en esta novela en la que se explora la modalidad autobiográfica de una forma inusitada, puesto que, desde las coordenadas espaciotemporales del Japón de la década de los sesenta, cuenta los primeros años de vida de un recién nacido.

Cualquier obra literaria es por naturaleza plurisignificativa y connotativa: detrás del significado obvio de la superficie se esconden múltiples sentidos, matices, alusiones y símbolos cuya captación dependerá, tanto de la pericia del emisor como de la competencia lectora del receptor, y si bien algunas obras acotan en gran medida sus posibilidades interpretativas, otras son mucho más susceptibles a las polifacéticas semantizaciones. Metafísica de los tubos, a priori, es el relato irónico y distanciado del mundo de los adultos, de sus complejas redes de relaciones y de sus pequeñas pasiones y miserias, desde la impostada voz de un infans, pero también es mucho más. En ese plus de significación intentaremos adentrarnos adoptando una de las muchas posibilidades exegéticas que la novela nos ofrece, y lo haremos haciendo hincapié en la construcción del personaje principal, cuyo desarrollo en la ficción ilustra perfectamente algunas de las tesis que, sobre la constitución del sujeto del inconsciente, configuran buena parte del ideario psicoanalítico, fundamentalmente el que se refiere a la preeminencia del significante sobre el sujeto. 


\section{Los resortes de una escritura autobiográfica: deseo, placer y búsqueda ontológica}

Poco después de que las primeras palabras de la novela nos abran las puertas del texto, la voz narrativa proporciona ya una doble clave a partir de la cual podemos aproximarnos a la escritura que plantea esta autora: por un lado, la rotunda afirmación sobre la existencia de una metáfisica de los tubos que viene refrendada por la reflexión que Slaworim Mrozek hizo en torno a estos objetos mediante palabras, o bien «abrumadoras en su profundidad o extraordinariamente desternillantes» $(M T, 9)^{1}$, lo que, en cierto sentido, supone una toma de conciencia de la naturaleza polar y ambigua del lenguaje, a la vez que pone el acento sobre la pluralidad de lecturas que el referente de este plantea; por otro, la alusión a la particular mezcla de plenitud y vacío que caracteriza dichos cilindros. Si la primera apunta al tono y contenido de la narración, la segunda nos sitúa de pleno en una ficcionalización del yo que pone en escena a un sujeto deseante que asume la función de narrar. Lo que subyace en ambas ideas converge en un título que anuncia una escritura atravesada por el humor -un humor que, valga decir, se mueve entre los meandros de la ironía, la acidez y la frivolidad-y una pregunta por el ser, una indagación en torno a propiedades, causas y principios ontológicos.

El género que por excelencia privilegia este tipo de discurso es la autobiografía. Si ya San Agustín se valió de él para revelársenos como un crápula arrepentido, en las dos últimas décadas se ha producido en el mercado editorial una avalancha de textos en los que el narrador se convierte en sujeto de la narración. En esta tendencia que la crítica contemporánea ha bautizado con el marbete de «literatura del yo» $\mathrm{o}$ «autoficción» se inscribe la novela que nos ocupará en lo que sigue.

Pues bien, Metafísica de los tubos nos sitúa ante un relato en primera persona de carácter retrospectivo que da cuenta de los primeros años de vida de un sujeto sin nombre, alrededor del cual las dos instancias narrativas que construyen la novela van ensamblando cualidades, atributos e imágenes que lo trazan como personaje. No obstante, el relato no arranca con la primera persona de la narración, sino con una significativa focalización omnisciente que observa, relata y valora, desde una posición externa al personaje, cómo este viene al mundo y establece sus primeros contactos con su entorno. El paso de la tercera persona a la primera, con

1. Todas las citas hacen referencia a la edición que Anagrama publicó en 2006. En el texto aparecerá entre paréntesis como $M T$ seguido del número de la página a la que pertenece el fragmento citado o las líneas en las que nos apoyamos para la interpretación que ofrecemos. 
todo lo que ello conlleva, se produce simultáneamente a la transformación que se opera en el tubo -significante con el que ambos narradores se refieren a la protagonista-, lo que pone de relieve la identificación entre narrador y personaje. La transformación que tiene lugar se produce en dos tiempos: lo que en la novela aparece bajo la denominación de «accidente mental» $(M T, 24)$ y la ulterior asunción de una identidad obtenida mediante el descubrimiento del placer $(M T, 35)$. Detengámonos en el primero de ellos.

Hasta ese momento el comportamiento pasivo e inerme del tubo es un caso incomprensible para el discurso científico $(M T, 27)$, ningún análisis o prueba médica es capaz de dar cuenta de la actitud de este bebé de dos años y medio que se niega a dar signos de vida. Pero ¿qué idea de movimiento puede tener un ser que está colmado, que es todo plenitud, que se describe como la «satisfacción absoluta»? $(M T, 7)$. Con estas sintomáticas palabras lo describe el narrador. El nuevo ser es Dios, una figura imposible de horadar por el deseo, que no quiere nada, porque nada desea. La voz narrativa consigna una captación imaginaria del niño: aquella mediante la cual él cree que no le falta nada, es decir, que se ve poseedor del falo $^{2}$, y aunque esto no explique su ingreso en la primacía fálica, necesario para su posterior desarrollo, el punto de partida de este bebé es precisamente esa presencia que hace que se sienta completo.

Sus atributos, como en el Dios bíblico, pasan por la vía negativa, es decir, se define a partir de lo que no es: sin mirada, sin movimiento, sin principio ni fin, sin lenguaje... ahora bien, con un cuerpo $(M T, 9)$. La materialidad orgánica que resulta atravesada originariamente sin mayor incidencia por los alimentos y los líquidos, devendrá en cuerpo cuando algo que le resulta insoportable aparece en su cerebro y lo empuja a gritar, es decir, a interpelar a otro. La demanda adviene e inmediatamente después la madre acude y «coge en brazos a su retoño» $(M T, 23)$, comenzando así una carrera colérica de gritos inexplicables que la madre interpreta como la recuperación de un tiempo perdido $(M T, 26)$. El narrador se apresura a rechazar esta interpretación, pero lo trascendental para la constitución de este futuro sujeto de la palabra, es que su madre traduce esos vagidos, los interpreta, y con ello introduce ya el patrón simbólico que hará posible su ubicación en el mundo. Una vez se articula la demanda en forma de grito y es atendida por la madre, el par au-

2. Definir aquí este compleja noción lacaniana sería tarea imposible, no obstante y puesto que se trata de un concepto imprescindible para la lectura que llevamos a cabo, nos contentaremos con decir que consiste en un significante -un operador si se prefiere- privilegiado que produce efectos de sentido, pero que en sí mismo está vacío. 
sencia-presencia queda establecido y se introduce ya la matriz simbólica que prepara para la inmersión definitiva (Lacan 2005: 61-78), dejando atrás la anterior afirmación de que «Dios carecía de lenguaje» $(M T, 16)$. Hasta ese momento no ha emitido el más mínimo sonido, lo que lo convierte en un ser que no sufre de lenguaje, aunque eso signifique también estar privado de vida. En este punto la narración en tercera persona y la que vendrá luego en primera coinciden en una certidumbre fundamental: la certeza de que son el lenguaje y el deseo los verdaderos garantes de la vida humana, aunque eso signifique también la definitiva incursión en el terreno de la insatisfacción y el sufrimiento.

Los vegetales clínicos «son lo que nos gustaría ser» $(M T, 21)$, asevera poco antes de ser barrado un sujeto que adivina ya en qué va a consistir una existencia movida por el deseo. Y así lo confirman las palabras que pronuncia poco antes de poner el broche a la novela con un conato de suicidio que aspira a poner fin a un deseo eternizado, marca del ser hablante:

Mira, pues. Mira con los ojos bien abiertos. La vida es lo que ves: membrana, tripas, un agujero sin fondo que exige ser rellenado. La vida es ese tubo que engulle y que permanece vacío. $(M T, 133)$

En la transformación del grito en demanda, la necesidad originaria de un sujeto sin deseo se pierde al depender de la lectura de un otro. Cuando la aya y la madre de la novela acuden a los gritos del bebé, transforman la demanda en un resto no articulado que se convierte en causa de deseo, un deseo que hace decir al narrador que dicho acontecimiento equivale al nacimiento. A partir de ese momento, y como contrapartida a la afirmación que mantiene en las primeras páginas donde se nos dice que ese Dios instalado en la Nada nada espera, el sujeto que sustenta la escritura se ve impulsado a una «búsqueda incesante por la realidad exterior para tratar de encontrar ese objeto perdido (en la articulación lingüística), respecto al cual, sin embargo, todos los objetos encontrados le resultarán siempre insatisfactorios» (Castrilo: 2011), lo que equivale a decir, en palabras de Slavoj Žižek, que «en esta búsqueda de Nada por convertirse en Algo [...] se reconoce la búsqueda misma del sujeto por el soporte sustancial» (2003: 217). Así las cosas, entendemos que el resorte de la escritura en esta novela bien podría ser el de historiar los orígenes de un sujeto en busca de una respuesta presumiblemente metafísica a la pregunta por el ser.

Ahora bien, no todo en esta recién estrenada vida se inscribe en el orden imaginario y simbólico; el empuje del cuerpo como real insiste de forma angustiosa en la experiencia vital de la protagonista confiriéndole consistencia al personaje, y esto se hace cada vez más patente conforme nos aproximamos a la conclusión 
de la novela. De este modo, si en una valoración inicial el narrador censura a los «imbéciles» que, casi convertidos en emblemas de la frigidez, exaltan sus capacidades intelectuales negando la sensualidad $(M T, 33)$ y hacen sucumbir el placer ante el peso de lo simbólico -lo que a una subjetividad como la de la protagonista de la novela le parece intolerable puesto que concibe su identidad a partir de las experiencias placenteras-, en el último tramo de la novela, y poco antes de arrojarse al estanque tras la repugnante visión de las carpas, asistimos a un nuevo e interesante chispazo de autoconsciencia por parte del infante, cuando se reconoce en una materialidad pura que apunta a aquello que escapa a la simbolización, a saber, la putrefacción del cuerpo, la atracción por la muerte $(M T, 133)$, lo que no obsta para que toda la novela se haga eco reiteradamente de la impronta que el lenguaje tiene en la construcción subjetiva.

La idea lacaniana de que el hombre está inmerso en un baño de lenguaje, que el registro simbólico es algo que le precede y constituye como sujeto, en definitiva, que su condición no es tanto de sapiens como loquens, es algo que Amélie Nothomb formaliza hábilmente en esta autoficción al convertir el código linguiístico en uno de los temas eje de la novela. Así se constata cuando la voz narrativa afirma que el lenguaje es lo que posibilita cualquier forma de pensamiento $(M T, 15)$, cuando lo ve como un instrumento de apropiación del mundo $(M T, 25)$, o cuando reflexiona sobre los efectos que produce: placer, creación, destrucción, vacuidad $(M T, 43)$. Si estos ejemplos son ya de por sí índices de la primacía que en el relato se le da a la palabra, más significativa es, sin duda, en este sentido, la inverosímil afirmación de que un ser de pocos meses de edad se considere a sí mismo perfectamente capaz de hablar, por más que sea incapaz de articular $(M T, 26,38)$.

Llegados a este punto, resulta inevitable detenerse brevemente para hacer una reflexión sobre el desdoblamiento subjetivo que el juego de narradores logra, así como de la importancia que la escritura tiene para el sujeto de la enunciación. Este paréntesis, además de arrojar algo de luz sobre las cuestiones apuntadas, servirá de bisagra entre las consideraciones anteriores en torno a la deuda simbólica que implica la castración ${ }^{3}$ y algunos apuntes sobre la posición femenina del sujeto que narra.

3. La castración, en el sentido lacaniano, es un concepto estrechamente vinculado al de falo y no responde a la concepción vulgar de mutilación del órgano sexual masculino, sino al de una función que organiza la lógica del tener o no tener, más allá de la percepción del órgano. Ya que la castración procede del lenguaje y traduce en forma dramática la perdida de goce que afecta al sujeto en tanto que es sujeto de lenguaje, esta es un operador que afecta a los dos sexos. 
En el pórtico de la novela, un narrador omnisciente nos habla en tercera persona sobre un recién nacido que es más bien «un segmento de materia sin vida» $(M T, 10)$, pero a los dos años y medio de edad, la Planta, que es como lo llaman los padres, arrebata la palabra a ese narrador externo y proclama con júbilo:

¡Soy yo! ¡Yo soy la que vive! ¡Yo soy la que habla! No soy «él» ni «este», ¡soy yo! Ya no tendrás que decir «él» para hablar de ti, tendrás que decir «yo». Y soy tu mejor amigo: el placer es mío. $(M T, 31)^{4}$

En la medida que este ser se inscribe en la red del gran Otro, aunque ficcionalmente esta entrada se dé en el pensamiento, el sujeto comienza a tener una existencia socio-simbólica, un lugar de enunciación en el que él pasa a ser un yo que permite al sujeto hablar de sí mismo, erigirse como objeto de su decir. Un relato en primera persona no es siempre una autobiografía, para que esta tenga lugar tiene que establecerse una mirada subjetiva en retrospección, y esto implica una selección en la que se privilegian unos acontecimientos y no otros: «La vida [léase novela] comienza donde empieza la mirada» $(M T, 8)$.

En esta misma dirección, y desde una perspectiva narratológica, aún se puede decir más, pues el carácter retrospectivo que asume un texto de estas características establece dos planos bien diferenciados: el de la instancia que se apropia de la narración y el del sujeto que vive los acontecimientos que se están narrando. Esta doble perspectiva permite, en ocasiones, un juego de actitudes que, si bien puede complicar la interpretación del texto en función de la armonía o la distancia que se establezca entre ambos niveles, también lo enriquece haciéndolo permeable a múltiples lecturas (Belic 1969: 29-31).

El viraje hacia la fórmula autobiográfica que plantea la novela desde la narración omnisciente, tiene importantes implicaciones para esta. La primera de ellas es que si tradicionalmente el carácter autobiográfico de una narración estaba revestido inevitablemente por el halo de la verdad, el caso que nos ocupa destruye en todo momento cualquier viso de autenticidad o verismo que pueda asomar, y no solo eso, sino que la estrategia que adopta para llevarlo a cabo equivale a una conspiración contra un concepto tan afín a la fórmula autobiográfica como el de la verosimilitud. La novela se postula, por tanto, como una suerte de apuesta por

4. El subrayado es nuestro. 
la ficcionalización de la verdad o, invirtiendo los términos, como una evidencia de la verdad que subyace en una ficción ${ }^{5}$.

Por si no fuera suficiente que sea un recién nacido quien se hace cargo de la voz narrativa, la nula aspiración a ser creído por el supuesto lector se patentiza a las claras cuando, primero, relata su vida a partir de los «testimonios de sus allegados» y no basándose en recuerdos que la edad ha borrado $(M T, 36)$, lo que equivale a decir que la verdad del asunto pasa por varios filtros que distorsionan los acontecimientos, siendo el último de ellos, y el más importante, el mismo código que le sirve como instrumento de expresión; segundo, que cuando, a modo de lo que podríamos considerar un ejercicio metaliterario, la pequeña protagonista se convierte en narradora para su hermana, dinamita la frontera que separa verdad y ficción igualando los términos a la vez que con ese gesto se reafirma en su papel creador: «Tenía que acostumbrarme a aquella idea: no tenía credibilidad», dice, «No era grave. En el fondo, me daba lo mismo que me creyeran o no. Yo seguiría inventando para mi propia satisfacción» $(M T, 106)$.

A lo que esta maniobra apunta -fuera de que tras esa afirmación queramos ver más al sujeto que narra que al que vive, y fuera también de que podamos interpretar estas líneas como una satisfacción obtenida por medio de la escritura con evidentes visos de sublimación- es a declarar que de lo que se trata es de poner en escena, no la Verdad esencial, sino una verdad que se constituye como tal en la medida en que esta pasa por el lenguaje, se hace literatura, se cifra en un código que se incorpora, como un significante más, a la cadena significante, tornándose susceptible de convertirse en verdad para otros sujetos.

El lugar de esa voz que resuena en la novela es el de un sujeto que de un estado vegetativo pasa a ser capaz de tener sed para beberse el universo entero $(M T, 101)$. La voracidad insaciable que marca esta voz y que anticipa ya el título de la siguiente novela de la autora-Biografía del hambre-, parece sucumbir en ocasiones bajo el peso de una pulsión de muerte que desmitifica, por otro lado, la convencional e idílica visión del mundo infantil. El intento de suicidio declarado, las dos ocasiones en las que está involuntariamente al borde la muerte, la fruición con la que reproduce los relatos de violencia y muerte que le cuenta su cuidadora Nishiosan, o la angustia estructural por el advenimiento de la muerte -noción de la que

5. La desautorización del narrador es un locus clasicus de la literatura posmoderna y de la que le precede, sin duda. Nothomb, aunque sigue estelas ya trazadas previamente, interesa en cuanto a que hace una propuesta novedosa y muy particular en este sentido. 
dice tener un alto grado de conciencia, pues no hay diferencia entre ella y la vida que ha llevado como planta $(M T, 44)$-, dan buena muestra de su atracción tanática. Ahora bien, esa querencia que la devolvería al estado inerme y abúlico del que partió es producto de un apetito voraz por la vida que se traduce en un miedo visceral a perderla. En otras palabras: es su contrapartida. Más aún, la percepción de la propia muerte, además de concebirse como un paraíso en donde todo lo que ha sido dado será arrebatado $(M T, 114)$, se subjetiva como un refugio seductor que, a modo de madriguera, permitiría a la protagonista deshacerse de su deseo, un deseo que el ser hablante percibe como motor de su experiencia vital, a la vez que como fuente inagotable de insatisfacción.

Y es que la muerte, como una madriguera, como una habitación con las persianas bajadas, como la soledad, es a la vez terrible y tentadora: uno siente que podría sentirse bien con ella. Bastaría abandonarse para reunirse con esa hibernación interior. Eurídice es tan seductora que tendemos a olvidar por qué hay que resistirse a su influjo. Y hay que hacerlo por la simple razón de que, en general, el trayecto es únicamente de ida. De no ser así, no sería necesario. $(M T, 46)$

Pero ¿cuál es el resorte que mueve al personaje a tomarse como objeto de su discurso? ¿A qué responde ese giro que hace que la voz narrativa pase a primer plano su propio acto de escritura? Previamente ya lo hemos apuntado: el segundo paso decisivo para el cambio de focalización es su encuentro con el placer. La primera clave la encontramos en un hecho aparentemente trivial y cotidiano como es el descubrimiento del chocolate. El placer que le produce la degustación de este dulce supone para la protagonista la conquista de su identidad, y esta se presenta indisolublemente unida en la novela a la adquisición de una memoria:

$\mathrm{Al}$ otorgarme una identidad, el chocolate blanco también me ha proporcionado una memoria [...]. Previo al chocolate blanco, no recuerdo nada: tengo que fiarme del testimonio de mis allegados, reinterpretado por mí. Luego mis informaciones son de primera mano: la misma mano que escribe. $(M T, 35-36)$

En esta última afirmación tenemos un fragmento de la piedra roseta que permite descifrar el acto de escritura que plantea Metafísica de los tubos; para acabar de comprenderlo hay que esperar al final de la novela, al momento en el que la equiparación recuerdo y escritura queda establecida:

[...] tienen el mismo poder [...] cuando ves la palabra «gato» escrita en un libro, su aspecto es muy diferente del minino de los vecinos, que te ha mirado con esos ojos tan hermosos. Y, sin embargo, ver esa palabra escrita te proporciona un placer similar a la presencia del gato, a su dorada mirada dirigida a ti. $(M T, 116)$ 
Por todo esto, podemos concluir que el yo, al dirigir su atención hacia sí mimo, convierte la escritura en un instrumento de autoindagación. Escribe también para dejar un rastro, un signo que le proporcione la certeza de que aquello que vivió fue real, de que su «aventura iniciática no [fue] un espejismo» $(M T, 143)$, y en este sentido, la cicatriz que atraviesa su frente, símbolo de su experiencia con la muerte, funciona como metáfora de ello. Por último, escribe porque de esa práctica obtiene un placer que, como tendremos ocasión de demostrar en lo que sigue, se constituye como algo que la identifica $(M T, 35)$. En definitiva, poco importa si estamos ante una novela que ficcionaliza un periodo de la vida de la autora o ante una pura invención que flirtea con el juego de la verdad, es por esto que podemos decir con Núria Girona que en el marco de la «ciencia-confesión [...] lo que se confiesa, solo por revelarlo, es verdad» (2008: 33).

\section{Investidura simbólica y filiación sexual}

Si volvemos a la jubilosa afirmación antes mencionada en la que el yo se introduce en el campo del logos mediante las fórmulas lingüísticas de « Soy yo! ¡ Yo soy la que vive! ¡Yo soy la que habla!», repararemos en que tras el milagro del chocolate, la voz narrativa, en un gesto de autorreconocimiento y exaltación, se nombra a sí misma, igualando, asimismo, vida y habla. Inmediatamente después, y por primera vez en la novela, aparece una marca lingüística que confiere a un ser hasta ese momento asexual -ha sido designado reiteradamente como «criatura», «tubo», «vegetal», o «planta»- una filiación del lado femenino.

Cuando la necesidad se convierte en deseo mediante la codificación lingüística ${ }^{6}$, el «segmento de materia» $(M T, 10)$ inerme con el que se asocia a la protagonista deviene sujeto, un sujeto que, tras esta primera voluptuosidad producida por la degustación del dulce, se identifica con la imagen del cilindro y se instala definitivamente en el ciclo interminable del deseo. Esta cautivadora imagen del vacío, junto a la preponderancia de la pulsión oral, tema que adquirirá un amplio desarrollo en otras novelas y aquí está mínimamente esbozado, constituyen, a nuestro juicio, los dos ejes sobre los que se construye el personaje. Este recurso, además, contribuye a equilibrar la balanza de la verosimilitud del relato, ya que si, por un lado, las capacidades intelectuales del protagonista, su lenguaje mental y su agudeza son atributos que demue-

6. «Por el hecho de que el hombre habla, las necesidades biológicas (la necesidad), quedan profundamente trastocadas en el hombre, perdidas en su naturalidad, para transformarse en otra realidad específicamente humana que Freud nombró deseo» (Castrilo, 2011). 
len la credibilidad, en los procesos de formación subjetiva que podemos apreciar, reconocemos un autentico bebé que camina hacia su maduración.

Podemos entender, pues, siguiendo a Freud, que la fruición con la que el personaje describe esta experiencia reproduce la primera satisfacción, aquella en la que el otro (generalmente la madre, pero no necesariamente debe ser así) aporta al bebé el objeto de la necesidad, produciendo una experiencia de satisfacción que deja una huella mnémica, de tal modo que cuando el estado de necesidad vuelve a surgir, el sujeto no solo espera que el otro le aporte el objeto de la necesidad, sino que provoca en él el impulso de volver a evocar la huella, aquella percepción enlazada con la primera satisfacción -lo que Freud llama deseo- (2007:109-225). El bebé que narra en Metafísica de los tubos acaba de experimentar la transformación del objeto de la necesidad en don: el agua ya no será solo agua que apaga la sed, las galletas o las guindas en almíbar se simbolizan y se convierten en indiscutibles pruebas de amor. Pero lo que se encuentra tras esa barra de chocolate que, además de lo ya dicho, va a erotizar los alimentos hasta hacer de ellos testimonios de amor, no es su madre, sino el rostro bondadoso de su abuela.

Leídas así las cosas podríamos preguntarnos, atendiendo a cierta lógica, por qué esta primera satisfacción se produce tan tardíamente, y por qué, y esta es una de las cuestiones más significativas de la novela, no es la madre la que provoca en el infans esa primera satisfacción, sobre todo si tenemos en cuenta que cuando aún no tiene un año esta intenta darle el pecho y «ante la visión del seno alimenticio ningún fulgor ilumin[a] los ojos del bebé» $(M T, 14)$.

Frente al objeto primitivo, el pecho materno (Lacan 2005: 69), el bebé tiene una reacción de rechazo que molesta a la madre haciendo que renuncie a amamantarla. El narrador en tercera persona, en una nueva exhibición de omnisciencia, afirma que esta última acierta, pues el tubo encontraba que «la rotundidad mamaria no le inspiraba ningún vínculo de familiaridad», no así la naturaleza cilíndrica de un biberón $(M T, 14)$. Si advertimos también -y no pretendemos encontrar una correspondencia rígida entre las escansiones que prototípicamente determinan la posición sexual de cada sujeto y las que nos parecen secuencias narrativas significativas que orienten nuestra interpretación- que el bebé rechaza, o no reacciona, ante otro regalo de la madre en forma de música de Mozart $(M T, 17)$; que más tarde se dice que su adquisición de la lengua nipona fue anterior a la de la lengua materna $(M T, 56)$; que, a diferencia del padre, es la madre la que riñe severamente e intenta impedir que la niña tome alimentos apetitosos $(M T, 54)$; la que le administra la azotaina del siglo $(M T, 75)$; la que en un vuelo imaginativo expresa desesperada su deseo de tirar a la niña por la ventana $(M T, 28)$; si observamos, de- 
cimos, todos estos motivos, podemos ver de qué manera se ha deslizado entre los dos planos narrativos -si no desde el nivel que los supervisa, esto es, la autorauna relación conflictiva con la madre que permite entrever un goce particular del sujeto femenino: el estrago (Alfonso 2011).

El peso que los personajes femeninos de la novela tienen sobre la protagonista es indiscutiblemente mucho más significativo que el de los personajes masculinos: «Quería a mi padre, toleraba a Hugo [...] pero consideraba a mi hermano la peor de las molestias» $(M T, 82)$, confiesa la pequeña pensando incluso en el exterminio de los hermanos mayores. En cambio, idolatra a su hermana Juliette hasta el punto de permanecer las noches en vela viéndola dormir y levantándose «descansada por el sueño de su hermana» $(M T, 76)$; ama a su abuela; adora a la «joven dulce y amable» Nishio-san, el aya que la trata como a una divinidad y le da de comer a escondidas $(M T, 51)$; incluso tiene muy presente a la bella aristócrata Kashima-san, a quien la niña desea seducir con sus encantos $(M T, 59)$. Parece innegable, pues, la fascinación que muestra por todas las manifestaciones femeninas que habitan en la novela, o mejor dicho, por los semblantes que estas representan. Gracia, bondad, dulzura, amabilidad, finura, altivez o belleza, se convierten en fascinantes emblemas que, en un primer momento lógico, por identificación narcisista con la imagen del otro, se convierten en parte de la estructura subjetiva (Bazzano; Gandolfo 2003). Estas presencias femeninas sustituyen a la madre, a la que la instancia narrativa soslaya reservándole un protagonismo esencial en las tres escenas en las que su primer objeto de amor le salva la vida: en el mar, en los barrotes de la ventana y en el estanque. La relación con la madre aparece de este modo marcada con el par característico de esta forma de goce, el del amor-odio/reproche.

De ahí que, y siguiendo con la línea que venimos trazando, no es casual que se explicite el hecho de que la niña dormía en la habitación de los padres $(M T, 16)$, y al poco tiempo, incómodos ante la mirada invasiva de esta, la expulsan a una especie de granero $(M T, 72)$. Aunque su mirada infantil recibe con regocijo este exilio, resulta imposible no pensar en una temprana separación de la madre que rompe con la relación idílica original propia de la fase preedípica.

En este punto, y antes de continuar, es necesario hacer un paréntesis. Lacan llama tríada imaginaria a la relación imaginaria fundamental que se articula en torno a tres vértices: madre, niño y falo (2005: 31). Este triángulo conceptual supone una fase inicial y decisiva que interviene directamente en la posición sexual del sujeto, ya que en ella media el significante fundamental -el falo- a partir del cual el sujeto debe posicionarse, bien en una lógica del todo, (entonces estaremos hablando de una posición masculina), bien en una lógica del no-todo, en cuyo caso 
hablaremos de una posición sexual femenina. El sexo biológico, por tanto, no impide al sujeto ubicarse en una posición o en otra; la anatomía no es la respuesta a la pregunta sobre la identidad sexual. Desde esta perspectiva se entiende que el psicoanálisis lacaniano lo que plantea es una clínica de la sexuación y no una clínica del género (Rubio 2011).

Después de esta breve aclaración teórica, volvemos al texto. A la relación ambivalente entre la madre y la niña que subyace en el relato, se superpone la presencia de un progenitor que, aunque no explícitamente, ejerce a su modo la función paterna, haciendo así posible algo que resulta fundamental para el proceso de constitución del sujeto del inconsciente, del sujeto como efecto de significante, a saber, descubrir su propia falta al descubrirla primeramente en su madre. El sujeto femenino no se identifica totalmente a la función madre. Hay algo que escapa o que pretende ser dejado de lado (Brousse 1993: 18). A los dos años y medio la protagonista ve que su madre «abraza a su padre como si de un gigantesco bebé se tratara» $(M T, 44) \mathrm{y}$, en ese momento, percibe que el deseo de la madre mira hacia otro lugar y va más allá del falo que la niña, imaginariamente, quiere representar para ella. Unas palabras de Esthela Solano-Suárez nos ayudarán a entender esta relación originaria que la novela transluce, y refrendarán, además, la idea anteriormente apuntada sobre la preponderancia de la pulsión oral en el bebé protagonista, cuya génesis hay que buscar en una erogenización de los alimentos.

La niñita introduce de manera fantasmática el falo bajo las especies del niño que ella quiere darle a la madre, o bien que quiere recibir de ella. Este niño fálico es un objeto metonímico que deriva de los objetos pulsionales. (Solano-Suárez 2003: 43)

Así entra en juego una lógica más allá del falo de la que la madre no podrá dar cuenta a su hija provocando en ella la eternización de la demanda y haciendo de la decepción algo connatural a su estructura. La pequeña, que aspira a colmar y ser colmada por la madre, percibe el desplazamiento que esta comienza a ejercer, un desplazamiento que culmina con la expulsión del tálamo matrimonial de los padres. Este suceso sumamente significativo se complementa magníficamente con uno de los pasajes más hilarantes de la novela, y también uno de los más simbólicos, aquel en el que la niña oye por primera vez a su padre practicando el canto $n o^{7}$. «Luego se puso a cantar. Reprimí una expresión de terror. ¿Qué eran aquellos extraños y

7. Se refiere a una de las tres facetas, la del canto, que conforman la práctica teatral japonesa conocida como Noh. 
espantoso sonidos procedentes de su vientre? ¿Cuál era aquel idioma incomprensible?» $(M T, 89)$, se pregunta atravesada por un profundo malestar. Fuera de la novedad de no haber escuchado nunca semejantes sonidos, no resulta extraño que, al poco de que se haya formalizado la percepción de la diferencia de los sexos, la niña interiorice el canto no de su padre como un «lamento irreconocible». Ese No se convierte en metáfora de la «voz paterna»-léase función-que obliga a abandonar a la madre como objeto de amor, que convierte al padre en un enemigo al que inocentemente abandona en una alcantarilla durante horas $(M T, 98)$ y que, finalmente, prohíbe a la madre como fuente de placer.

En estos momentos cruciales se origina el estrago, cuando la niña pide subsistencia a la madre -lo que no puede obtener puesto que se trata de algo que no puede ser simbolizado- y se dirige al padre en busca del falo, desarrollando una manifiesta hostilidad hacia la madre que cristaliza en la novela tal y como hemos puntualizado: con rechazo, eclipsamiento y neutralización de su figura ${ }^{8}$. Ahora bien, paradójicamente -como resto imborrable de aquella relación amorosa, origen de las primeras sensaciones placenteras- es a la madre a quien reserva una función salvífica, pues es ella la que la libra de una muerte segura, por más que, en consonancia con el tono pesimista y demoledor de muchos pasajes, para la niña haber sobrevivido solo es una escapatoria momentánea: «un día, ya no será posible andarse con dilaciones, y ni siquiera las personas mejor intencionadas del mundo podrán hacer nada» $(M T, 143)$.

Amélie Nothomb focaliza su autobiografía en los tres primeros años de su vida, y en los siguientes términos expresa el narrador una sentencia que bien podría entenderse como clave de lectura: «la mirada es una elección. El que mira parece fijarse en algo concreto y, por consiguiente, a la fuerza elige excluir su atención del resto de su campo visual. Esa es la razón por la cual la mirada, que constituye la esencia de la vida es, en primera instancia, un rechazo» $(M T, 17)$. Esa posibilidad del narrador que elige incluir o excluir acontecimientos - clara referencia a la novelización de su vida que se fundamenta en una manipulación que incluye una alteración del orden de los acontecimientos y una selección- es lo que, junto a las

8. Al entrar en el terreno del estrago estamos en el último Lacan, quien en este punto cruzó el límite en el que Freud se dio contra la pregunta-muro: «¿Qué quiere una mujer?» -más allá del falo, añadimos-. La respuesta de Lacan apunta, no al tener o no tener freudiano, sino al ser, no colmando el agujero, sino asimilándolo, dialectizándolo o siendo el agujero. Solo desde el lado femenino se puede declarar la falsedad del ser colmado. El rechazo al falo (en forma de carpa) que al final de la novela puede leerse como chispa momentánea, puede entenderse como denuncia del falo como semblante, lo que no implica que la posición femenina nada tenga que ver con un goce fálico. 
características de la novela, abre vías interpretativas más laxas, aun en el caso de que pensásemos que es necesario encontrar en el interior del texto literario la $a u$ torización para hacerlo.

Así pues, y en estrecha relación con las consideraciones previas, la impostada voz infantil, con conciencia de que existe una diferencia entre mujeres y hombresconciencia que parece haber adquirido con sorpresa ante la calificación japonesa de un mar-macho y un océano-hembra $(M T, 64)-$, descubre en el florido mes de mayo que hay una diferencia sexual que puede llegar a perturbarla. La diferencia entre hombres y mujeres que en un principio le parece una oposición como otra cualquiera, se le revela por primera vez como algo «mucho más importante» $(M T$, 78). La primera cuestión sobre la diferencia la establece en términos de igualdad social. Le parece bien que haya un símbolo del sexo masculino, el mástil y la carpa, y un mes de los chicos, pero la pregunta no se hace esperar: « $i Y$ cuándo cae el mes de las chicas»? (MT, 78). La respuesta la deja estupefacta - «No existe»-, y en lo que parece un gesto antiandrocéntrico, propina una patada a un mástil que sintomáticamente, en plena correspondencia con algunas desigualdades que sobreviven en nuestros días, permanece imperturbable.

Aunque la novela no insista en las implicaciones sociales y políticas que el género como representación tiene en la vida material de los individuos (Lauretis 2000: 36), sí marca la discriminación y la injusticia de cierta desigualdad que quizá resulte aún más acentuada en el caso de oriente. Por otro lado, hay que hacer notar también el hecho de que el personaje señale con dolor cómo Hugo y su hermano, bajo el inevitable efecto de lo que De Lauretis llama «tecnología del género»efecto indudablemente bajo el que todos estamos, no solo ellos- se posicionan en un lugar que les autoriza a silenciar un discurso que se interroga por esta diferencia, lo que implica que, entendido así el género, es decir, como un conjunto de relaciones sociales que penetra toda la existencia social, este afecte tanto a hombres como mujeres, siendo una fuerza que «incide sobre [la]construcción subjetiva» a la vez que «esa representación subjetiva del género incide sobre su construcción social» (Lauretis 2000: 42-43).

Hecha esta precisión, nos encontramos en la tesitura de que la niña se interroga sobre lo que representa esa carpa que ondea en lo alto del mástil erigiéndose como símbolo de la masculinidad: «¿En qué evoca más a mi hermano que a mí?» $(M T$, 78), se dice evidenciando con ello que la percepción de la diferencia anatómica está ya en circulación. Si en un principio, y estamos en Freud, el falo es para el niño un atributo universal, en este punto de la novela se inaugura en esta niña, a nivel imaginario, la percepción de la falta, que en su caso debe ser subjetivada. La 
lógica freudiana es una lógica que se centra para los dos sexos en la cuestión del falo. Tener o no tener el falo, esa es la cuestión. La primera impresión que le produce la visión de este símbolo fálico es descrita con un tono de fascinación:

Llegamos al estanque. Observé un hormiguero de colores. En la otra orilla un bonzo se acercó a tirar unos gránulos. Vi cómo las carpas saltaban para alcanzarlos: Algunas eran enormes: Era un brote refulgente [...] uno sólo podía contemplar su chispeante colorido a la luz y maravillarse. $(M T, 80)$

Pero inmediatamente después de esta aparente fascinación por lo masculino, surge el asco ante este animal «símbolo del sexo feo», emerge una repugnancia que se acentúa cuando en lugar del elefante de peluche que ella quiere, lo que no podemos dejar de tomar como otra representación simbólica del falo que la lleva a una decepción sin palabras $(M T, 121)$, sus padres le regalan tres carpas. Son peces que le causan un desprecio infinito rayano en la obsesión: «Este es mi cuerpo y yo os lo ofrezco», dice entregándose como animal propiciatorio. Con esta eucarística y no menos irónica frase, la narradora nos coloca ante la escena de un fantasma primordial que, en estrecha vinculación con la relación erótico-amorosa con la madre, se erige como reconstrucción a la que recurre el sujeto para obtener una satisfacción autoerótica (Lacan 2005: 115-123).

Hablar del fantasma no implica hablar de perversión, aunque este esté construido con el discurso perverso; en cambio, hablar de este fantasma sí implica que la función paterna está ya instaurada en el sujeto, lo que nos sitúa en el dominio de la neurosis y ratifica una idea que hemos apuntado anteriormente, a saber: la del padre que prohíbe. El fantasma de este sujeto, un fantasma que, valga decir, tiene como paradigma teórico el «pegan a un niño» freudiano, puede interpretarse como el deseo de esta niña de ser apartada de la madre, de distanciarse de su objeto primordial. Pegar, ser pegado; mirar, ser mirado; o comer, ser comido, resultan posibles vías imaginarias que convierten el goce en placer, lo que sin duda es mucho más soportable para el sujeto.

Que el mismo acto de comer resulta enormemente placentero es algo que la voz narrativa declara reiteradamente y sin ambages en el desarrollo de la novela. Al llegar a las últimas páginas de esta nos encontramos con que ser comida tiene el mismo efecto placentero que comer, aunque quizá sea menos consciente ya que este hecho no deja de presentársele como un enigma que la define como ser individual: «A veces pienso que nuestra única especificidad individual radica precisamente en esto: dime lo que te da asco y te diré quién eres» $(M T, 125)$, declara al encontrar en sus propias repulsiones una marca de identidad. 
Y aún ahonda más en ese asco que le producen los peces. Bajo la forma de un imperativo escamoteado bajo el humor, el equívoco y la negación -el clásico tópico tradicional del carpe diem, interpretado por ella como «una carpa al día»- se articula (o ficcionaliza, es lo mismo) un modo de goce que, como tal, se polariza entre el placer y el displacer:

\begin{abstract}
Tenía la impresión de que era mi carne la que alimentaba a las carpas: adelgacé. Tras la comida de los peces, me llamaban para comer; no podía probar bocado [...] De noche, en mi cama, la oscuridad se poblaba de bocas abiertas. Bajo mi almohada, lloraba de terror. La autosugestión era tan intensa que los enormes cuerpos escamosos y flexibles me acompañaban entre las sábana, me abrazaban, y su jeta bezuda y fría me morreaba. Era la impúber amante de fantasmas pisciformes [...] No era su estómago lo que me repugnaba, sino su boca, el movimiento de válvula de sus mandíbulas que me violaba los labios durante eternidades nocturnas. (MT, 126-7)
\end{abstract}

La atracción y repulsión que esta particularísima representación fálica ejerce en el sujeto que narra se traduce en vértigo horrorizado, en espasmo del cuerpo y de la mente, en consternación de los sentidos y en sudores fríos $(M T, 125)$. Lo que culmina como una suerte de fantasía erótica infantil entre la que se cuela la mirada adulta de la narradora, que puede interpretarse como un deseo que oscila entre el anhelo de trasmutar el objeto sexual que hasta ese momento era la madre, figura que amenaza bajo imágenes de devoramiento, y el anhelo expresado en forma de pregunta de acabar eternizándose como falo que colme a la madre: «¿acaso iba a cambiar de especie? ¿no iba a convertirme en pez? Mis manos recorrían mi cuerpo, al acecho de alucinantes metamorfosis» $(M T, 127)$.

Si al comienzo de nuestra reflexión remitíamos interesadamente a una marca lingüística que apuntaba al género femenino ( «Soy yo la que habla»), llegados a este punto debemos admitir que esa marca se sustrae al discurso novelístico en favor de fórmulas neutras e indeterminadas, si bien es cierto que una narración en primera persona favorece esta ausencia de morfemas genéricos. Con todo podemos decir que, siguiendo la lógica que nos ha traído hasta aquí, la posición sexuada de cada sujeto, cuyo eje de articulación es el significante falo, tiene una temporalidad retroactiva que opera en la pubertad, por lo que si seguimos el juego que nos propone Amélie Nothomb, es algo que, al menos dentro de la ficción, estaría todavía por determinar, por mucho que hayamos creído vislumbrar algunas luces al respecto.

Para concluir, y puesto que la novela presenta una indiscutible modulación humorística, y teniendo en cuenta que en el principio del witz (el chiste) se encuentra el falo que da sentido a la sexualidad (Freud 1986) -en el sentido de que este está siempre comprometido en el asunto (Solano-Suárez 2003: 51)-, podemos afir- 
mar, apropiándonos del tono de la narración, que sí, efectivamente, la novela va de eso, de eso que no deja de ser un misterio para quien narra $(M T, 125)$, y que, gracias a las posibilidades que la creación literaria le ofrece, permite a este sujeto transportarse hasta «aquel tiempo de infancia, [en el que] la relación con el lenguaje es tan próxima que [...] ]evoca directamente la relación del lenguaje con el deseo, lo que constituye la satisfacción propia del chiste» (Lacan 2009: 131).

\section{Bibliografía}

ALFONSO, G. «Sexualidad o posición femenina» http://www.elpcvalenciana.arrakis.es/Textos/Sexualidad\%20o\%20posici\%F3n\%20femenina.htm. (Acceso 7 de abril de 2011).

ASENSI PÉREZ, M. (2003). «Psicoanálisis y literatura», en Historia de la teoría de la literatura (el siglo XX hasta los años setenta), Valencia, Tirant lo Blanch, II: 523-596.

BAZZANO, B. y GANDOLFO, R. (2003). «Precisiones sobre el complejo de castración y la noción de falo», Psicólogos: revista de psicología de la Universidad Nacional de Tucumán, 13 (13): 137-145.

BELIC, O. (1969). Análisis estructural de textos hispánicos, Madrid, Prensa Española.

BROUSSE, M.-H. (1993). «Madre o mujer», Correo del campo freudiano en Andalucía, 13: 15-20.

CASTRILO MIRAT, D. «Necesidad, demanda deseo», http://www.olavarria.com/ ciudad/universitarios/biblioteca/descargas/m/DEMANDA,NECESIDAD\%20 Y\%20DESEO.pdf. (Acceso 22 de abril de 2011).

FREUD, S. 2007 (1953). «Tres ensayos de teoría sexual», en Obras completas, vol. 7, Buenos Aires-Madrid, Amorrortu, 2007. Traducción de José Luis Etcheverry.

GIRONA FIBLA, N. (2008). Rituales de la verdad. Mujeres y discurso en América Latina, Méjico-París, RDEHL.

LACAN, J. 2005 (1994). Seminario IV. La relación de objeto, Buenos Aires, Paidós. Traducción de Enric Berenguer.

__, 2009 (1999). Seminario V. Las formaciones del inconsciente, Buenos Aires, Paidós. Traducción de Enric Berenguer.

LAURETIS, T. de. (2000). Diferencias. Etapas de un camino a través del feminismo, Madrid, Horas y Horas.

NOTHOMB, A. 2009 (2000). Metafísica de los tubos, Barcelona, Anagrama. Traducción de Sergi Pàmies. 
RUBIO, R. «Identidad y género», http://www.elpcvalenciana.arrakis.es/textos.htm (Acceso 8 de abril de 2011).

SOLANO-SUÁREZ, E. (2003). «Dolor de la femineidad: entre el ser y la existencia», en Clínica lacaniana, Buenos Aires, Tres Haches.

ŽIŽEK, S. (2003). Las metástasis del goce, Buenos Aires, Paidós. 